\title{
Benzylammonium-Mediated Formamidinium Lead Iodide Perovskite Phase Stabilization for Photovoltaics
}

Anwar Q. Alanazi, ${ }^{1}$ Masaud H. Almalki, ${ }^{1}$ Aditya Mishra, ${ }^{2}$ Dominik J. Kubicki, ${ }^{1,2}$ Zaiwei Wang, ${ }^{3}$ Lena Merten, ${ }^{4}$ Felix T. Eickemeyer, ${ }^{1}$ Hong Zhang, ${ }^{1}$ Dan Ren, ${ }^{1}$ Ahmed Y. Alyamani, ${ }^{5}$ Hamad Albrithen, ${ }^{5,6,7}$ Abdulrahman Albadri, ${ }^{5}$ Mohammad Hayal Alotaibi, ${ }^{5}$ Alexander Hinderhofer,${ }^{4}$ Shaik M. Zakeeruddin, ${ }^{1}$ Frank Schreiber ${ }^{4}$, Anders Hagfeldt ${ }^{3}$ Lyndon Emsley, ${ }^{2 *}$ Jovana V. Milić, ${ }^{{ }^{*}}$ and Michael Graetzel ${ }^{{ }^{*}}$

Anwar Q. Alanazi, Masaud H. Almalki, Dr. Hong Zhang, Dr. Dan Ren, Dr. Shaik M. Zakeeruddin, Dr. Jovana V. Milić, and Prof. Michael Graetzel

${ }^{1}$ Laboratory of Photonics and Interfaces, Institute of Chemical Sciences and Engineering, School of Basic Sciences, Ecole Polytechnique Fédérale de Lausanne, CH-1015 Lausanne, Switzerland.

Aditya Mishra, Dr. Dominik J. Kubicki and Prof. Lyndon Emsley

${ }^{2}$ Laboratory of Magnetic Resonance, Institute of Chemical Sciences and Engineering, School of Basic Sciences, Ecole Polytechnique Fédérale de Lausanne, CH-1015 Lausanne, Switzerland.

Zaiwei Wang and Prof. Anders Hagfeldt

${ }^{3}$ Laboratory of Photomolecular Science Institute of Chemical Sciences Engineering Ecole Polytechnique Fedérale de Lausanne (EPFL) Lausanne 1015, Switzerland

Lena Merten, and Dr. Alexander Hinderhofer and Prof. Frank Schreiber

${ }^{4}$ Institut für Angewandte Physik, Universitaet Tübingen, Auf der Morgenstelle 10, 72076 Tübingen, Germany

Dr. Ahmed Y. Alyamani, Dr. Hamad Albrithen, Dr. Abdulrahman Albadri, and Dr. Mohammad Hayal Alotaibi

${ }^{5}$ National Center for Nanotechnology, King Abdulaziz City for Science and Technology, P.O. Box 6086, Riyadh 11442, Saudi Arabia.

Dr. Hamad Albrithen

${ }^{6}$ Physics and Astronomy Department-Research Chair for Tribology, Surface and Interface Sciences, College of Science, and King Abdullah Institute for Nanotechnology-Aramco Laboratory for Applied Sensing Research, King Saud University, P.O. Box 2455, Riyadh 11451, Saudi Arabia.

${ }^{7}$ K.A.CARE Energy Research and Innovation Center at Riyadh, Riyadh, Saudi Arabia.

\section{Corresponding authors:}

Prof. Lyndon Emsley lyndon.emsley@epfl.ch, Dr. Jovana V. Milić jovana.milic@epfl.ch, and Prof. Michael Graetzel michael.graetzel@epfl.ch

Keywords: low-dimensional perovskites, solid-state NMR, benzylammonium, formamidinium lead iodide 


\section{WILEY-VCH}

\section{Abstract}

There is an ongoing surge of interest in the use of formamidinium (FA) lead iodide perovskites in photovoltaics due to their exceptional optoelectronic properties. However, thermodynamic instability of the desired cubic perovskite phase $\left(\alpha-\mathrm{FAPbI}_{3}\right)$ at ambient conditions leads to the formation of a yellow non-perovskite $\left(\delta-\mathrm{FAPbI}_{3}\right)$ phase that compromises its utility. We achieve a stable $\alpha-\mathrm{FAPbI}_{3}$ perovskite phase by employing benzylammonium iodide (BzI) and elucidate the microscopic structure by using solid-state NMR spectroscopy and X-ray scattering measurements. Perovskite solar cells based on the $\mathrm{FAPbI}_{3}(\mathrm{BzI})_{0.25}$ composition achieve power conversion efficiencies exceeding $20 \%$, which is accompanied by enhanced shelf-life and operational stability, maintaining $80 \%$ of the performance after one year at ambient conditions.

\section{Introduction}

Hybrid organic-inorganic perovskite solar cells (PSCs) have seen an unprecedented increase in photovoltaic performance over the last decade, rising from $3.8 \%$ to over $25 \% .^{[1,2]}$ This stunning improvement can be ascribed to the perovskite absorber materials, which are ionic crystals possessing high dielectric constants, long charge carrier diffusion lengths, large absorption coefficients, and a band gap suitable for solar light harvesting. ${ }^{[3-8]}$ These materials are based on the $\mathrm{ABX}_{3}$ structure (Figure 1a-b), where $\mathrm{A}$ is a monovalent cation, e.g. organic methylammonium (MA), formamidinium (FA), or inorganic $\mathrm{Cs}^{+}, \mathrm{B}$ is a divalent metal (such as $\mathrm{Pb}$ or $\mathrm{Sn})$, and $\mathrm{X}$ is a halide ion $\left(\mathrm{Cl}^{-}, \mathrm{Br}^{-}\right.$, or $\left.\mathrm{I}^{-}\right) \cdot{ }^{[9]}$ Perovskite properties are tunable by replacing the large halide (e.g. $\mathrm{I}^{-}$) by smaller size halides (e.g. $\mathrm{Br}^{-}$), which results in an increase in the band gap. ${ }^{[10]}$ while substituting $\mathrm{Pb}^{2+}$ by $\mathrm{Sn}^{2+}$ decreases the band gap. ${ }^{[11]}$ 


\section{WILEY-VCH}

a)

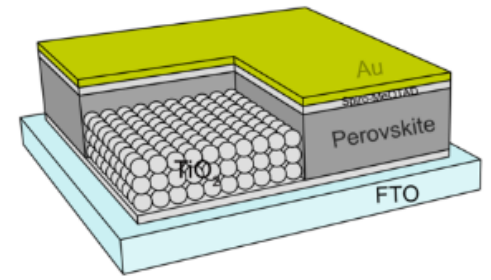

b) $\mathrm{ABX}_{3}$

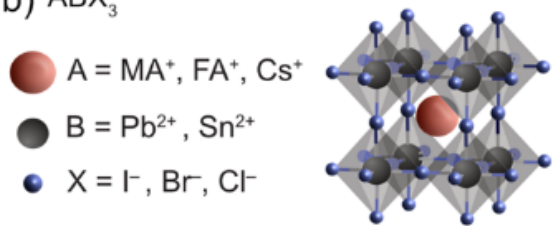

C) $S_{x} A_{n-1} B_{n} X_{3 n+1}$

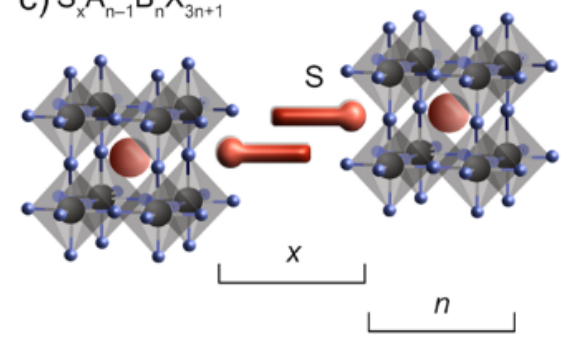

Figure 1. Schematic representation of (a) a perovskite solar cell as well as the (b) 3D perovskite crystal structure based on an $\mathrm{ABX}_{3}$ formulation along with the (c) typical layered 2D perovskite structure based on $S_{x} A_{n-1} B_{n} X_{3 n+1}$ formula. For instance, the presented $2 D$ structure can be defined by the $x=2$ (Ruddlesden-Popper phase) and $n=2$ composition.

Another approach to tailoring the optoelectronic properties includes the use of larger organic cations to form low-dimensional perovskites. ${ }^{[12,13]}$ This approach leads to an increase in the band gap as a result of modifying the 3D perovskite structure by introducing layers of organic spacer moieties within the $3 \mathrm{D}$ structure, to form a layered $2 \mathrm{D}$ perovskite structure. ${ }^{[14,15]}$ The general formula for the $2 \mathrm{D}$ perovskite systems is $\mathrm{S}_{\mathrm{x}} \mathrm{A}_{\mathrm{n}-1} \mathrm{~B}_{\mathrm{n}} \mathrm{X}_{3 \mathrm{n}+1}$, where $x$ depends on the number of large alkylammonium cations in the layer ( $x$ mostly equals 1 or 2 ), whereas $n$ defines the number of perovskite slabs separated by the organic layer $(n=1,2,3$, etc.; Figure 1c $) .{ }^{[13,14,16,17]}$ Spacers are large organic alkylammonium cations that can be either mono- $(x=2)$ or bifunctional $(x=1)$ to produce 2D-perovskite Ruddlesden-Popper (RP) or Dion-Jacobson (DJ) phases, respectively. ${ }^{[13,17-21]}$ The electrical and optical properties of materials strongly depend on the number of $3 \mathrm{D}$ perovskite slabs $(n)$ separated by the $2 \mathrm{D}$ layers, which are mainly comprised of insulating organic moieties. ${ }^{[22]}$ Therefore, these systems are highly anisotropic 


\section{WILEY-VCH}

and the effective charge extraction depends on the orientation of the layers with respect to the selective charge-extraction layers. ${ }^{[12,23]}$ This limitation stimulated the appearance of another approach that involves forming $2 \mathrm{D} / 3 \mathrm{D}$ perovskite composites of $3 \mathrm{D}$ perovskite compositions with 2D overlayers, which show good photovoltaic performance with improvement in their operational stability. ${ }^{[24-29]}$ In this regard, 2-phenylethylammonium (PEA) has been particularly effective (Figure 2a). ${ }^{[20,30-33]}$ It has been shown that phenylalkylammonium analogues, e.g. benzylamine and aniline, can impart the formamidinium (FA) lead iodide film surface with improved electronic properties and moisture resistance. ${ }^{[34]}$ The remarkable optoelectronic properties of $\alpha-\mathrm{FAPbI}_{3}$ and its high thermal stability render it an ideal candidate for hybrid perovskite photovoltaics. ${ }^{[35-36]}$ However, under ambient temperature conditions, $\alpha-\mathrm{FAPbI}_{3}$ perovskite converts to the non-perovskite $\delta$-phase that is not suitable for photovoltaics and stabilizing it without compromising the optoelectronic properties as well as device performances is an ongoing challenge. ${ }^{[36]}$ The use of phenylammonium analogues on the surface of $\mathrm{FA}_{0.9} \mathrm{Cs}_{0.1} \mathrm{PbI}_{2.9} \mathrm{Br}_{0.1}$ films shows promise for suppressing hysteresis effects, ${ }^{[36]}$ whereas benzylammonium (Bz; Figure 2b) gave promising results, ${ }^{[35-36]}$ although its role in perovskite solar cells remain elusive.

Herein, we demonstrate stabilization of the $\alpha-\mathrm{FAPbI}_{3}$ phase by modifying it with benzylammonium $(\mathrm{Bz})$ cations. Benzylamine features a delocalized $\pi$-system ${ }^{[37,38]}$ extending over the entire molecule, as shown by the density functional theory calculations ${ }^{[39]}$ which could contribute to lowering the barrier for charge-carrier transport as compared to other phenyl analogs. Moreover, the $\mathrm{Bz}$ features strong hydrophobicity ${ }^{[34]}$ and rigidity, without compromising the adaptability of the ammonium termini for binding to the perovskite surface. ${ }^{[40,41]}$ This could further direct the assembly of $\mathrm{Bz}$ moieties on the surface of $\alpha-\mathrm{FAPbI}_{3},{ }^{[42]}$ while maintaining its optoelectronic properties. ${ }^{[28]} \mathrm{We}$ reveal that BzI can interact with $\alpha-\mathrm{FAPbI}_{3}$ at the atomic level through hydrogen bonding, as evidenced by solid-state NMR spectroscopy, stabilizing it 


\section{WILEY-VCH}

against the detrimental $\alpha$-to- $\delta$ phase transition. Furthermore, adding BzI to the perovskite precursor $\left(\right.$ abbreviated as $\left.\mathrm{FAPbI}_{3}(\mathrm{BzI})_{\mathrm{x}}\right)$ leads to superior device performance and operational stability, as well as shelf-life over one year under ambient conditions.

\section{Results and discussion}

We prepared hybrid perovskite films by dissolving the $\mathrm{FAI}, \mathrm{PbI}_{2}$ and BzI precursors in a mixture of $N, N$-dimethylformamide (DMF) and dimethyl sulfoxide (DMSO) of 4:1 volume ratio and depositing the precursor solution by spin coating it onto the electron selective contact

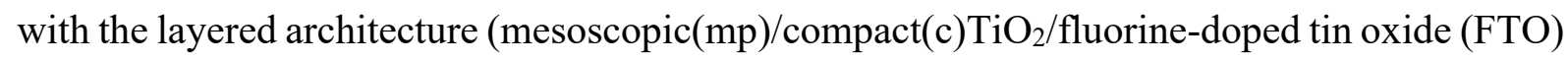
glass; Figure 1a). The details of the procedure are given in the Experimental Section.

The structural properties of the films are analyzed by X-ray diffraction (XRD) for different $\mathrm{FAPbI}_{3}(\mathrm{BzI})_{\mathrm{x}}$ compositions $(\mathrm{x}=0,0.05,0.10,0.25$ and 0.50$)$. The films containing $\mathrm{Bz}$ moieties show patterns comparable to the $3 \mathrm{D} \mathrm{FAPbI}_{3}$ perovskite (Figure 2c). While the propensity of $\mathrm{Bz}$ to form a pure $2 \mathrm{D} \mathrm{Bz}_{2} \mathrm{PbI}_{4}$ perovskite is evidenced by XRD (Figure S1), there are no additional peaks observed in the lower angle domain $\left(2 \theta<10^{\circ}\right)$ for $\mathrm{FAPbI}_{3}(\mathrm{BzI})_{\mathrm{x}}$ which suggests the absence of low-dimensional perovskite phases under these conditions. ${ }^{[17]}$ Moreover, the film of $\mathrm{FAPbI}_{3}(\mathrm{BzI})_{0.25}$ does not show the presence of diffraction peaks associated with $\mathrm{Bz}_{2} \mathrm{PbI}_{4}$, as reported previously. ${ }^{[43]}$ In this earlier report, however, a strong reflection signal has been observed at $6.26^{\circ}$, which is not apparent for the films containing FAI. This suggests that the 2D phase either does not form in the presence of FAI or that it is highly disordered which prevents its detection. Alternatively, multiple low-dimensional phases of various mixed Bz/FA 2D/3D phases are likely to form, which could co-exist in lower concentrations and possibly feature lower level of crystallinity, leading to the disappearance of the low angle reflection peaks or their appearance in a different $2 \theta$ range. Nevertheless, other spectral signatures suggest presence of the interaction with the $\mathrm{FAPbI}_{3}$. Specifically, while neat $\mathrm{FAPbI}_{3}$ films contain $\delta$ - 


\section{WILEY-VCH}

FAPbI $_{3}\left(2 \theta=11.8^{\circ}\right)$ and $\mathrm{PbI}_{2}\left(2 \theta=12.6^{\circ}\right),{ }^{[44,45,40]}$ these phases are absent in the films containing Bz, particularly for $\mathrm{x}>0.05$ compositions. This suggests that Bz affects the structure of $\mathrm{FAPbI}_{3}$, which could be the result of surface modification or the formation of mixed lowdimensional Bz/FA phases. ${ }^{[42]}$
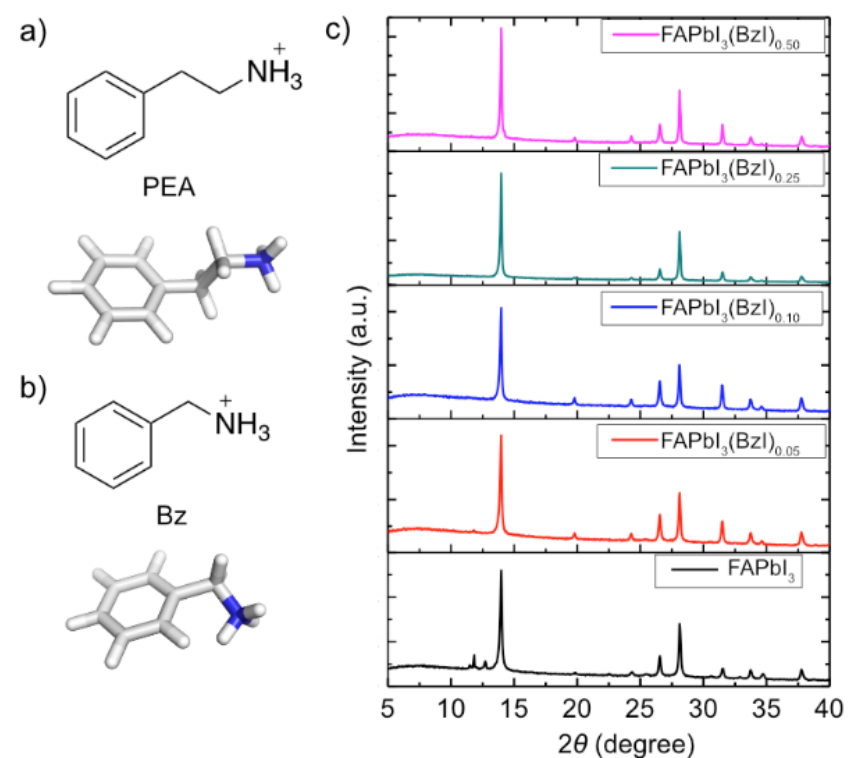

Figure 2. (a-b) Structural representation of (a) commonly employed 2-phenylethylammonium (PEA) organic spacers for 2D perovskites and (b) benzylammonium (Bz) organic moieties employed in this study with the corresponding DFT-optimized structures (at the B3LYP 6-31G(d) level of theory). ${ }^{[4]}$ (c) XRD patterns of the $\mathrm{FAPbI}_{3}(\mathrm{BzI})_{\times}$perovskite films.

This interaction was further assessed at the atomic-level by means of solid-state NMR spectroscopy. It has been shown that the solid-state NMR methods can be employed to investigate phase-segregation ${ }^{[47-50]}$, cation-incorporation ${ }^{[51]}$, cation-dynamics ${ }^{[52-54]}$, halide mixing ${ }^{[49]}$, and atomic-level proximities among various functional groups. ${ }^{[55]}{ }^{1} \mathrm{H}-{ }^{13} \mathrm{C}$ crosspolarization experiments were performed on neat BzI and $\mathrm{FAPbI}_{3}(\mathrm{BzI})_{0.25}$ samples (Figure 3, left) prepared by mechanosynthesis in accordance with the reported procedures. ${ }^{[47-50]}$ The NMR spectra of $\alpha-\mathrm{FAPbI}_{3}$ and $\delta-\mathrm{FAPbI}_{3}$ show distinguishable ${ }^{13} \mathrm{C}$ resonances at $155.9 \mathrm{ppm}$ and 156.8 ppm, respectively (Figure 3a-b), while neat BzI shows aliphatic ${ }^{13} \mathrm{C}$ resonances at $43.3 \mathrm{ppm}$ and six aromatic resonances in the 125-136 ppm range (Figure 3c). In $\mathrm{FAPbI}_{3}(\mathrm{BzI})_{0.25}$, the FA environments appear at $155.9 \mathrm{ppm}$ evidencing the stabilization of the 


\section{WILEY-VCH}

$\alpha-\mathrm{FAPbI}_{3}$ phase. Moreover, the aliphatic (40-50 ppm) and aromatic (125-136 ppm) signals of $\mathrm{Bz}$ are shifted compared to neat BzI, indicating that BzI has fully reacted with $\mathrm{FAPbI}_{3}$ (Figure 3d). We initially assumed that this reaction might result in the formation of low-dimensional $\mathrm{Bz}_{2} \mathrm{FA}_{n-1} \mathrm{~Pb}_{\mathrm{n}} \mathrm{I}_{3 \mathrm{n}+1}$ phases (with $n=1,2,3, \ldots$ ) co-existing with the $3 \mathrm{D} \mathrm{FAPbI}_{3}$ perovskite phase, likely in accordance with the following reaction (1). This would require the release of FAI as one of the side-products, which is known to be more volatile and/or act as a passivation agent.

$$
\mathrm{FAI}+\mathrm{PbI}_{2}+0.25 \mathrm{BzI} \rightarrow(0.875-0.125 n-\mathrm{x}) \mathrm{FAPbI}_{3}+0.125 \mathrm{Bz}_{2} \mathrm{FA}_{\mathrm{n}-1} \mathrm{~Pb}_{\mathrm{n}} \mathrm{I}_{3 \mathrm{n}+1}+\mathrm{xFAI}
$$

Grazing-Incidence Wide-Angle X-ray Scattering (GIWAXS) measurements of $n=1-3$ compositions, however, could not detect these in co-existence with the $3 \mathrm{D}$ perovskite within the $\mathrm{FAPbI}_{3}(\mathrm{BzI})_{0.25}$ composition, despite the capacity of BzI to form low-dimensional phases (Figure S2-S3, Supporting Information). Instead, it shows a predominant formation of the 3D $\mathrm{FAPbI}_{3}$ perovskite phase, suggesting its role as a molecular modulator at the surface and grain boundaries of $\mathrm{FAPbI}_{3}$. This stabilization is in keeping with the previous reports on the structuredirecting role of molecular modulators that template the $\alpha-\mathrm{FAPbI}_{3}$ phase and alter the energy landscape for the interconversion to the $\delta$ - phase, hence stabilizing it. ${ }^{[56-57]}$
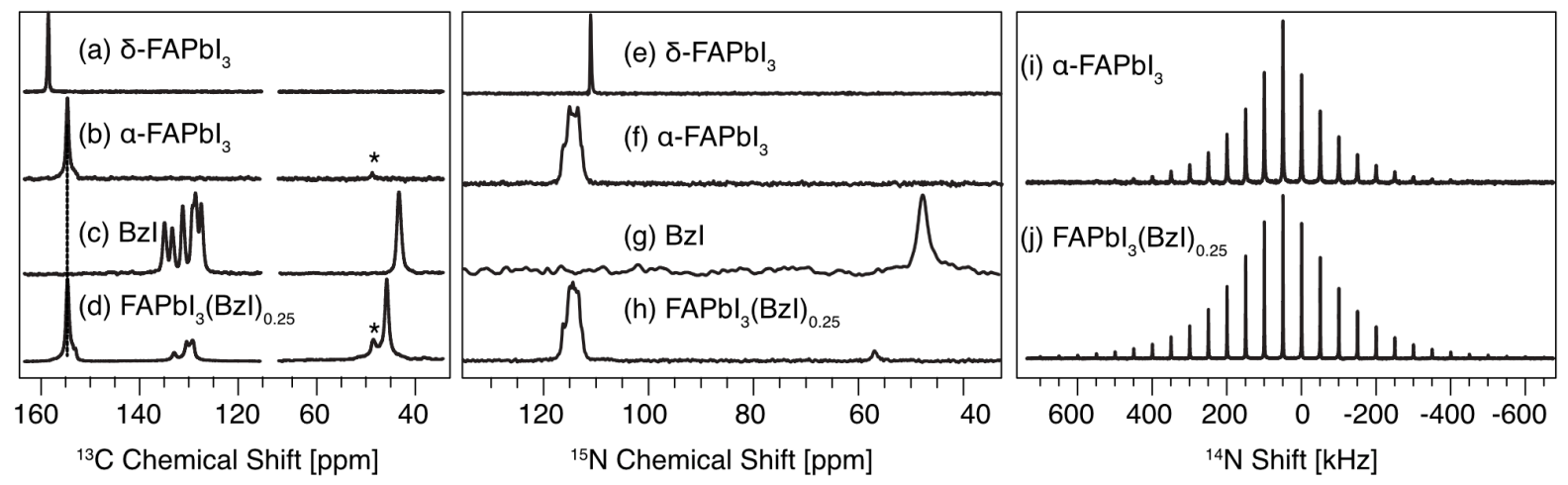

Figure 3. $(\mathrm{a}-\mathrm{d})^{1} \mathrm{H}_{-}{ }^{13} \mathrm{C}$ cross-polarization $(\mathrm{CP})$ with $12 \mathrm{kHz}$ magic-angle spinning (MAS) at $100 \mathrm{~K}$ and $21.1 \mathrm{~T}$ of bulk microcrystalline a) $\delta$-FAPbI 3 , b) $\alpha-\mathrm{FAPbI}_{3}$, c) BzI, and d) $\mathrm{FAPbI}_{3}(\mathrm{BzI})_{0.25}$. (e-h) ${ }^{1} \mathrm{H}-{ }^{15} \mathrm{~N}$ cross-polarization (CP) with $12 \mathrm{kHz}$ magic-angle spinning (MAS) at $100 \mathrm{~K} \mathrm{e}$ ) $\left.\delta-\mathrm{FAPbI}_{3}, \mathrm{f}\right) \alpha-\mathrm{FAPbI}_{3}$, g) BzI, and h) $\mathrm{FAPbI}_{3}(\mathrm{BzI})_{0.25} .{ }^{14} \mathrm{~N}$ MAS NMR at $5 \mathrm{kHz}$ MAS, $298 \mathrm{~K}$ and $21.1 \mathrm{~T}$ of i) $\alpha-\mathrm{FAPbI}_{3}$ and j) $\mathrm{FAPbI}_{3}(\mathrm{BzI})_{0.25}$. 


\section{WILEY-VCH}

To further corroborate the atomic-level FA/Bz mixing, we performed low-temperature ${ }^{1} \mathrm{H}-{ }^{15} \mathrm{~N}$ cross-polarization (CP) measurements (Figure 3e-h), which reveal the local chemical environment of the $-\mathrm{NH}_{3}$ moieties in $\mathrm{BzI}$ and $\mathrm{FA} . \delta-\mathrm{FAPbI}_{3}, \alpha-\mathrm{FAPbI}_{3}$ and $\mathrm{BzI}$ show wellresolved ${ }^{15} \mathrm{~N}$ resonances at 111.0, 114.2 and $47.9 \mathrm{ppm}$, respectively. In BzI-doped $\mathrm{FAPbI}_{3}$, the Bz signal (56.9 ppm) is significantly shifted compared to neat BzI. This is accompanied by a change in the lineshape of the signal corresponding to the 3D FA environments, which suggests that the local structure of the perovskite phase is modified by the reaction with BzI (Figure 3h). This further corroborates the formation of a mixed Bz/FA phase which we identify as the direct reason for the observed stabilization effects. The Bz/FA interaction may also affect the symmetry of the cuboctahedral cavity, which we in turn probe using ${ }^{14} \mathrm{~N}$ NMR spectroscopy. ${ }^{14} \mathrm{~N}$ spectra of hybrid perovskites provide complementary insights into crystallographic changes on the local level owing to their sensitivity to the symmetry around the fast-reorienting A-site cation. ${ }^{[28,58]}$ Specifically, ${ }^{14} \mathrm{~N}$ magic angle spinning (MAS) NMR spectra feature a spinning sideband (SSB) manifold whose width is highly sensitive to the symmetry of the local environment. ${ }^{14} \mathrm{~N}$ MAS NMR of $\mathrm{FAPbI}_{3}(\mathrm{BzI})_{0.25}$ exhibits full width at half maximum (FWHM) of $120 \mathrm{kHz}$ (Figure 3j), which is broader compared to $\alpha-\mathrm{FAPbI}_{3}$ with $\mathrm{FWHM}$ of $70 \mathrm{kHz}$ (Figure 3i), suggesting that the presence of BzI perturbs the symmetry of the cuboctahedral cavity, making it less cubic compared to the pristine $\alpha-\mathrm{FAPbI}_{3}$.

We further analyzed the effect of BzI addition on the morphology of the $\mathrm{FAPbI}_{3}$ films by means of scanning electron microscopy (SEM; Figure S4). The changes in the morphology are apparent as the films based on the $\mathrm{x}=0.10$ composition appear smoother, while those of the $\mathrm{x}$ $=0.25$ and 0.5 compositions show more surface roughness. This roughness can contribute to an increase of the contact area with the hole transporting material in the resulting device. In addition, the effect of BzI on the thickness is apparent via the cross-sectional images of $\mathrm{FAPbI}_{3}$ and $\mathrm{FAPbI}_{3}(\mathrm{BzI})_{0.25}$ layers (Figure S4), showing a slight difference in thicknesses, which can 


\section{WILEY-VCH}

be attributed to the changes in the grain size of the $\mathrm{FAPbI}_{3}(\mathrm{BzI})_{0.25}$ film. The effect of Bz moieties on the optical properties was also apparent, as shown by UV-vis absorption spectroscopy (Figure 4a). While UV-vis absorption spectra of the control and the films containing 25\% BzI exhibit no change in the absorption edge, there is an increase in the absorbance in the spectral range below $600 \mathrm{~nm}$ (Figure S5a). There are no clear indicators of the presence of $\mathrm{Bz}_{2} \mathrm{PbI}_{4}$ phase in the absorption spectra. Specifically, the absorption spectra of the films based on $\mathrm{FAPbI}_{3}(\mathrm{BzI})_{0.25}$ composition show an onset at $830 \mathrm{~nm}$, which suggests that the presence of BzI at this quantity does not compromise the optoelectronic properties of $\mathrm{FAPbI}_{3}$. Moreover, steady state photoluminescence (PL) spectra for neat $\mathrm{FAPbI}_{3}$ and $\mathrm{FAPbI}_{3}(\mathrm{BzI})_{\mathrm{x}}$ films show maximum emission peaks at $810 \mathrm{~nm}$ consistent with the $3 \mathrm{D} \mathrm{FAPbI}_{3}$ phase (Figure $4 \mathbf{b}$ ) without clear evidence for the presence of the $(\mathrm{Bz})_{2} \mathrm{PbI}_{4}$ phase in the $\mathrm{FAPbI}_{3}(\mathrm{BzI})_{0.25}$ film (Figure S5b). ${ }^{[59-}$ ${ }^{60]}$ The incident photon-to-current conversion efficiency (IPCE) spectra of $\alpha-\mathrm{FAPbI}_{3}$ and $\alpha-$ $\mathrm{FAPbI}_{3}(\mathrm{BzI})_{0.25}$ (Figure 4c) match the absorption edge of the photocurrent for the control and champion $\alpha$-FAPbI ${ }_{3}(\mathrm{BzI})_{0.25}$-containing perovskite devices in the fluorine doped tin oxide (FTO)/compact (c) $\mathrm{TiO}_{2} /$ mesoporous (mp) $\mathrm{TiO}_{2} /$ perovskite/ 2,2',7,7'-tetrakis-(N,N-di-4methoxyphenylamino)-9,9'-spirobifluorene (spiro-OMeTAD)/ $\mathrm{Au}$ architecture. The IPCE increases up to $60 \%$ around $400 \mathrm{~nm}$ and decreases to $10 \%$ at $800 \mathrm{~nm}$ for neat $\mathrm{FAPbI}_{3}$, presumably due to the existence of the $\delta$ phase. On the contrary, the IPCE retains about $80 \%$ for $\mathrm{FAPbI}_{3}(\mathrm{Bz})_{0.25}$ throughout the entire spectral range between $400 \mathrm{~nm}$ and $830 \mathrm{~nm}$, which highlights the stabilization effect that is particularly relevant for the photovoltaic performance. 


\section{WILEY-VCH}
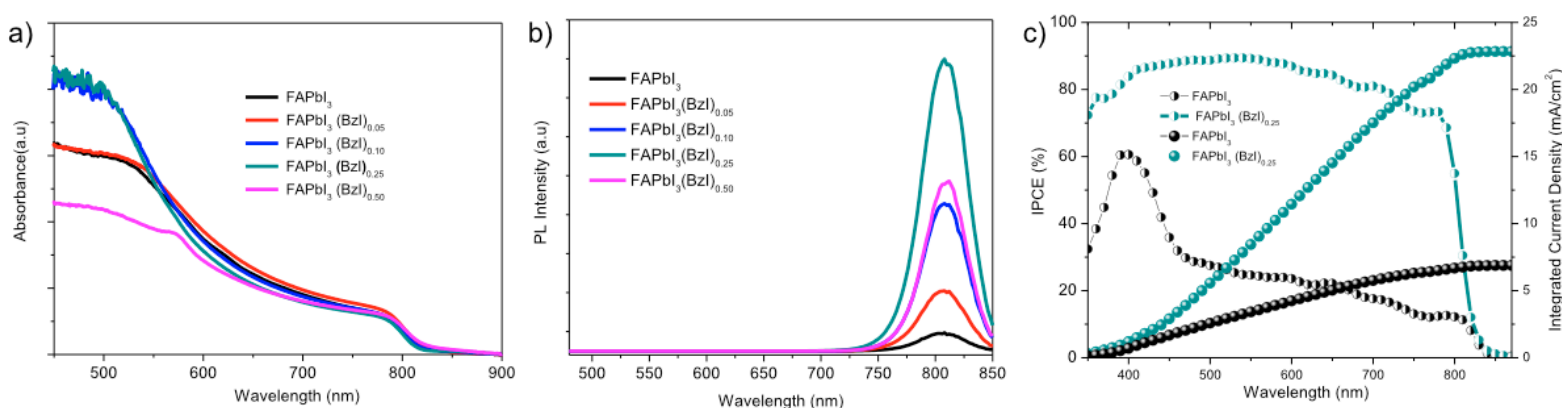

Figure 4. Characterization of the $\mathrm{FAPbI}_{3}(\mathrm{BzI})_{\mathrm{x}}$ perovskite films of various compositions $(x)$. (a) UVvis absorption, (b) photoluminescence, and (c) IPCE spectra (half spherical point; left Y-axis) with the integrated $J_{s c}$ (Full spherical point; right $\mathrm{Y}$-axis) of the $\alpha-\mathrm{FAPbI}_{3}$ and $\mathrm{FAPbI}_{3}(\mathrm{BzI})_{0.25}$ devices.

Photovoltaic performance was analyzed for devices based on $\mathrm{FAPbI}_{3}(\mathrm{BzI})_{\mathrm{x}}(\mathrm{x}=0,0.05,0.10$, 0.25 , and 0.50$)$ compositions by employing $\mathrm{FTO} / \mathrm{c}-\mathrm{TiO}_{2} / \mathrm{mp}-\mathrm{TiO}_{2} /$ perovskite/spiro$\mathrm{OMeTAD} / \mathrm{Au}$ device architecture and extracting the corresponding photovoltaic parameters under simulated 1.5 sunlight and a $J-V$ scan rate of $40 \mathrm{mV} \cdot \mathrm{s}^{-1}$ (Figure 5). The control devices containing neat $\mathrm{FAPbI}_{3}(\mathrm{x}=0)$ show a poor performance with a maximum power conversion efficiency (PCE) of 6.97\%, open circuit voltage $\left(V_{O C}\right)$ of $0.88 \mathrm{~V}$, short circuit current density $\left(J_{S C}\right)$ of $17.84 \mathrm{~mA} \cdot \mathrm{cm}^{-2}$, and a fill factor $(\mathrm{FF})$ of 0.55 (Figure S6a). The device performance gradually improves with the increase of the Bz ratio from $5 \%$ to $25 \%$, after which it declines with further increase of the BzI content. This decline in performance can be attributed to the insulating character of the organic moieties that would result in poor conductivity for higher BzI quantities. The champion device based on the $25 \%$ BzI achieved a maximum PCE of $20.2 \%$ with a $V_{O C}$ of $1.1 \mathrm{~V}, J_{S C}$ of $25 \mathrm{~mA} \mathrm{~cm}^{-2}$, and $F F$ of $73 \%$ (Figure S6b). The presence of BzI affects also the hysteresis in the $J-V$ curves, which was probed by $J-V$ scans with a rate of 40 $\mathrm{mVs}^{-1}$ for $\mathrm{FAPbI}_{3}$ and $\mathrm{FAPbI}_{3}(\mathrm{BzI})_{0.25}$ devices (Figure S6c, d). The data reveal lower hysteresis for the $\mathrm{FAPbI}_{3}(\mathrm{BzI})_{0.25}$ compositions in comparison with the control. 

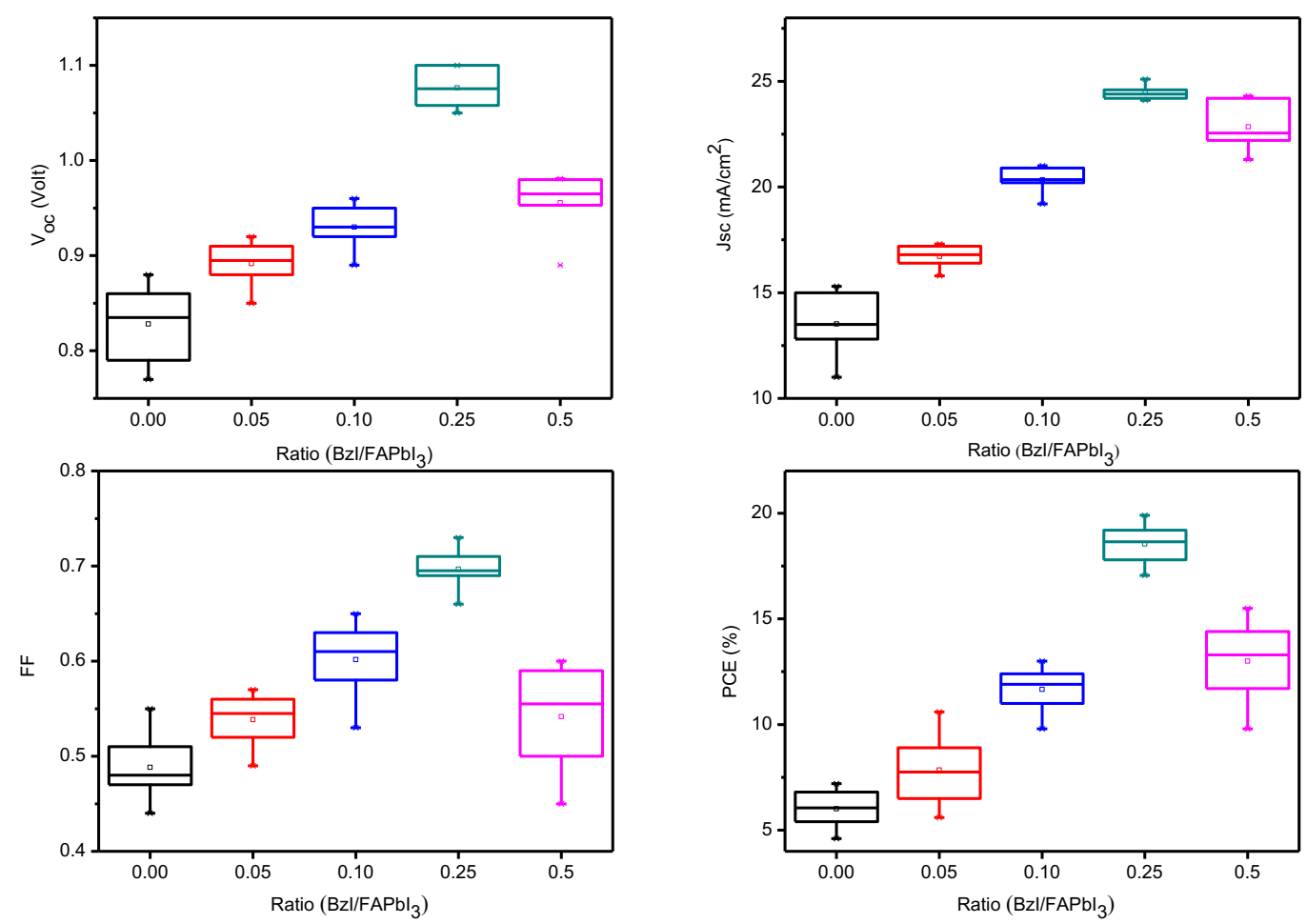

Figure 5. Photovoltaic parameters for 20 devices based on $\mathrm{FAPbI}_{3}(\mathrm{BzI})_{\mathrm{x}}(\mathrm{x}=0,0.05,0.10,0.25,0.50)$ perovskite composition.

To determine the origin of the $V_{\mathrm{OC}}$ and FF increase observed with the BzI treated devices, we carried out steady-state photoluminescence quantum yield (PLQY) and time-resolved photoluminescence (TRPL) measurements (Figure 6). PLQY was determined by absolute PL spectral photon flux measurements at one sun condition using an integrating sphere (Figure 6a). ${ }^{[61]}$ The BzI-treated device shows an order of magnitude higher PLQY than the untreated device. A PLQY $<1$ translates into a voltage loss due to non-radiative recombination of $\Delta V=$ $-k_{B} T / q \ln (P L Q Y)$ and a quasi-Fermi level splitting $\Delta E_{F}$ of $\Delta E_{F}=V_{\mathrm{OC}, \mathrm{SQ}}+\Delta V$, where $k_{\mathrm{B}}$ is the Boltzmann constant, $\mathrm{T}=25{ }^{\circ} \mathrm{C}$ the sample temperature, $q$ the elementary charge and $V_{\mathrm{OC}, \mathrm{SQ}}$ the Shockley-Queisser limit of $V_{\mathrm{OC}}{ }^{[62]} \Delta E_{F} / q$ is the internal voltage of the absorber layer, which represents the maximum obtainable $V_{\mathrm{OC}}$ of a device with this absorber. 

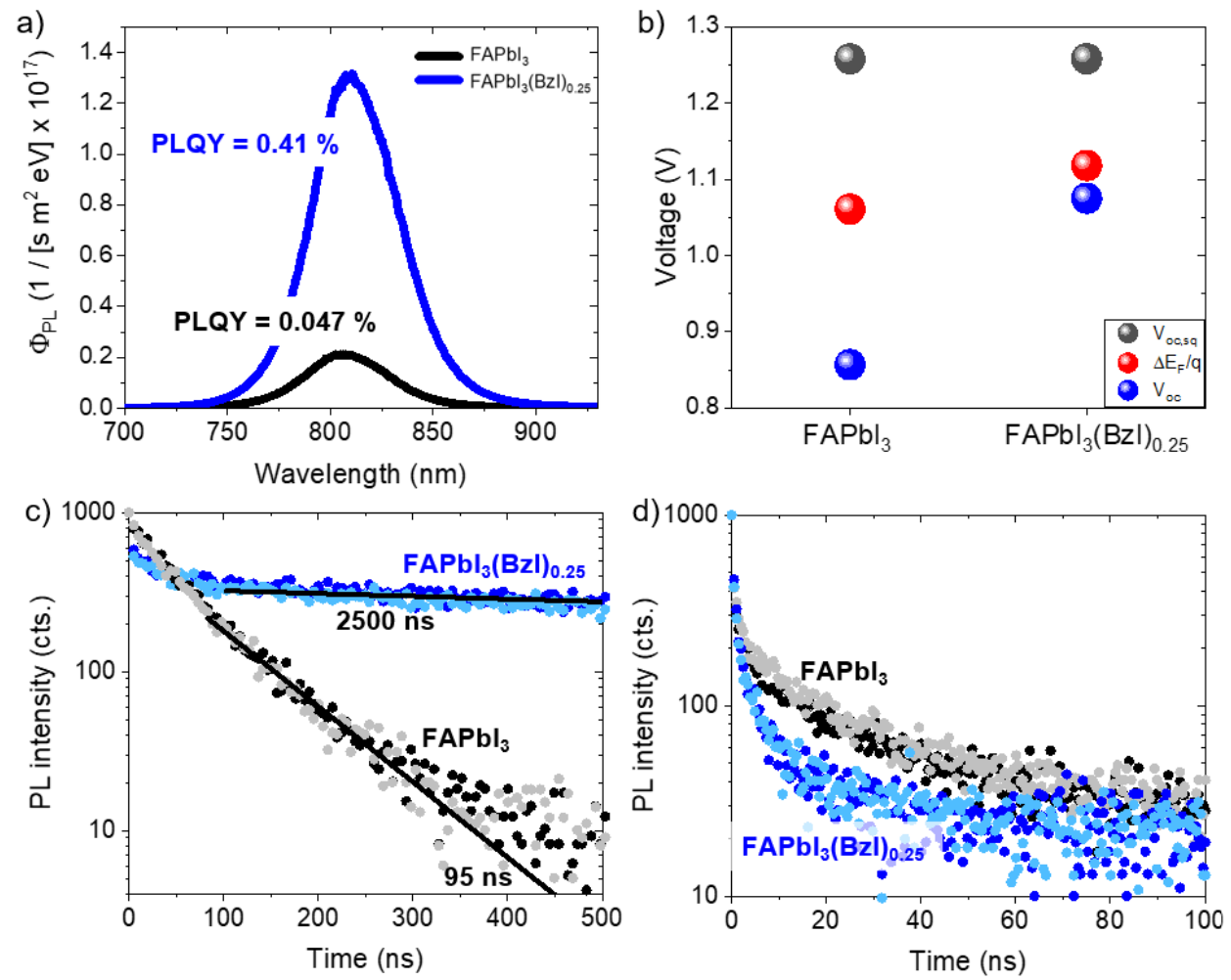

Figure 6. (a) Absolute PL spectral photon flux measurements of complete solar cell devices using $\mathrm{FAPbI}_{3}$ and $(\mathrm{BzI})_{0.25} \mathrm{FAPbI}_{3}$. (b) Quasi-Fermi level splitting $\triangle \mathrm{E}_{\mathrm{F}}$ determined from PLQY of the devices in a). Shown are also the Shockley-Queisser limit of $V_{\mathrm{OC}}\left(V_{\mathrm{OC}}, \mathrm{sQ}\right)$ and the measured $V_{\mathrm{OC}}$ of the same devices. (c) Time-resolved PL traces for the neat $\mathrm{FAPbI}_{3}$ and $(\mathrm{BzI})_{0.25} \mathrm{FAPbI}_{3}$ samples with the architecture $\mathrm{FTO} / \mathrm{c}-\mathrm{TiO}_{2} / \mathrm{mp}-\mathrm{TiO}_{2} /$ perovskite. Shown are the traces of two independent samples for each condition (circles) and mono-exponential fit curves (black lines) with the respective lifetimes. All measured curves start at 1000 cts. d) Same measurements as in c) but with spiro-OMeTAD on top of the perovskite layer.

If we compare $\Delta E_{F}$ with the stabilized $V_{\mathrm{OC}}$ measured with the same device (Figure 6b) we observe that both follow the same trend. The mismatch between these two quantities originates from the combination of energy level misalignments at the perovskite/ $\mathrm{TiO}_{2}$ and perovskite/spiro-OMeTAD interface in combination with radationless interfacial charge carrier recombination. ${ }^{[63]}$ These findings show that the increase in $V_{\mathrm{OC}}$ can be attributed to suppressed trap-assisted non-radiative recombination which demonstrates the beneficial effect of the BzI modulation on the defect chemistry. Since non-radiative recombination lower the $\mathrm{FF},{ }^{[64]}$ this also explains in part the FF increase of the BzI-modulated $\mathrm{FAPbI}_{3}$ device. 


\section{WILEY-VCH}

Furthermore, the TRPL traces of neat $\mathrm{FAPbI}_{3}$ and $(\mathrm{BzI})_{0.25} \mathrm{FAPbI}_{3}$ samples with mp-TiO ${ }_{2}$ but without HTM (Figure 6c) reveal two features, a fast decay within the first 50-100 ns followed by a slower mono-exponential decay. The fast decay at early times is dominated by charge transfer from the perovskite film into $\mathrm{TiO}_{2}{ }^{[65]}$ whereas the later decay is mainly caused by nonradiative bulk, interface or surface recombination of the perovskite film. The BzI treatment leads to a faster electron transfer into the ETL and to 25 times longer carrier lifetime $(\tau)$. Assuming that these lifetimes are dominated by bulk recombination, the measured $\tau$ values yield a non-radiative monomolecular $(\mathrm{SRH})$ recombination constant $k_{1}=1 /(2 \tau)$ of $5.3 \cdot 10^{6} \mathrm{~s}^{-1}$ for the neat and $2.0 \cdot 10^{5} \mathrm{~s}^{-1}$ for the BzI-modulated perovskite film. This further demonstrates the beneficial effect of BzI on the defect chemistry of the $\mathrm{FAPbI}_{3}$ film and is in good agreement with the improvement in the $V_{\mathrm{OC}}$ and FF. To investigate the effect of the BzI modulation on hole transport into the HTL, we measured TRPL on samples with spiro-OMeTAD (Figure 6d). In this case, the fast-initial decay within the first $50 \mathrm{~ns}$ is again dominated by charge transfer. The faster PL decay for the BzI-modulated film shows its beneficial effect on the hole transfer into the HTL. As a result, BzI treatment leads to a faster electron and hole transfer which is further contributing to an increase in FF.

Moreover, the maximum power point (MPP) tracking of the $\mathrm{FAPbI}_{3}(\mathrm{BzI})_{0.25}$ device shows a stable PCE of $20.0 \%$ after 300 seconds of constant 1.5 AM illumination (Figure S6e), indicating stabilization of the maximum power output. We have also monitored the shelfstability of the devices during one year under ambient conditions and we measured the $J-V$ for two unencapsulated devices of $\mathrm{FAPbI}_{3}$ and $\mathrm{FAPbI}_{3}(\mathrm{BzI})_{0.25}$. The control devices based on $\mathrm{FAPbI}_{3}$ showed a rapid decline in performance, whereas devices based on the $\mathrm{FAPbI}_{3}(\mathrm{BzI})_{0.25}$ composition maintain $80 \%$ of the initial PCE over one year under ambient (shelf-life) conditions (Figure 7a). The effects of these structural properties on the long-term operational stability were further probed under continuous AM1.5G irradiation $\left(100 \mathrm{~mW} \mathrm{~cm}{ }^{-2}\right)$ and 


\section{WILEY-VCH}

maximum power point tracking in a nitrogen atmosphere at room temperature (Figure 7b). The comparison of the neat $\mathrm{FAPbI}_{3}$ and $\mathrm{FAPbI}_{3}(\mathrm{BzI})_{0.25}$-based PSC shows that the operational stability of the $\mathrm{FAPbI}_{3}(\mathrm{BzI})_{0.25}$-based device is greatly improved, retaining $85 \%$ of its initial PCE up to $140 \mathrm{~h}$. On the contrary, the PCE of neat $\alpha-\mathrm{FAPbI}_{3}$ device declines rapidly and reaches $10 \%$ of its initial efficiency within $100 \mathrm{~h}$. This highlights the potential of this approach in achieving PSCs with long-term stability.
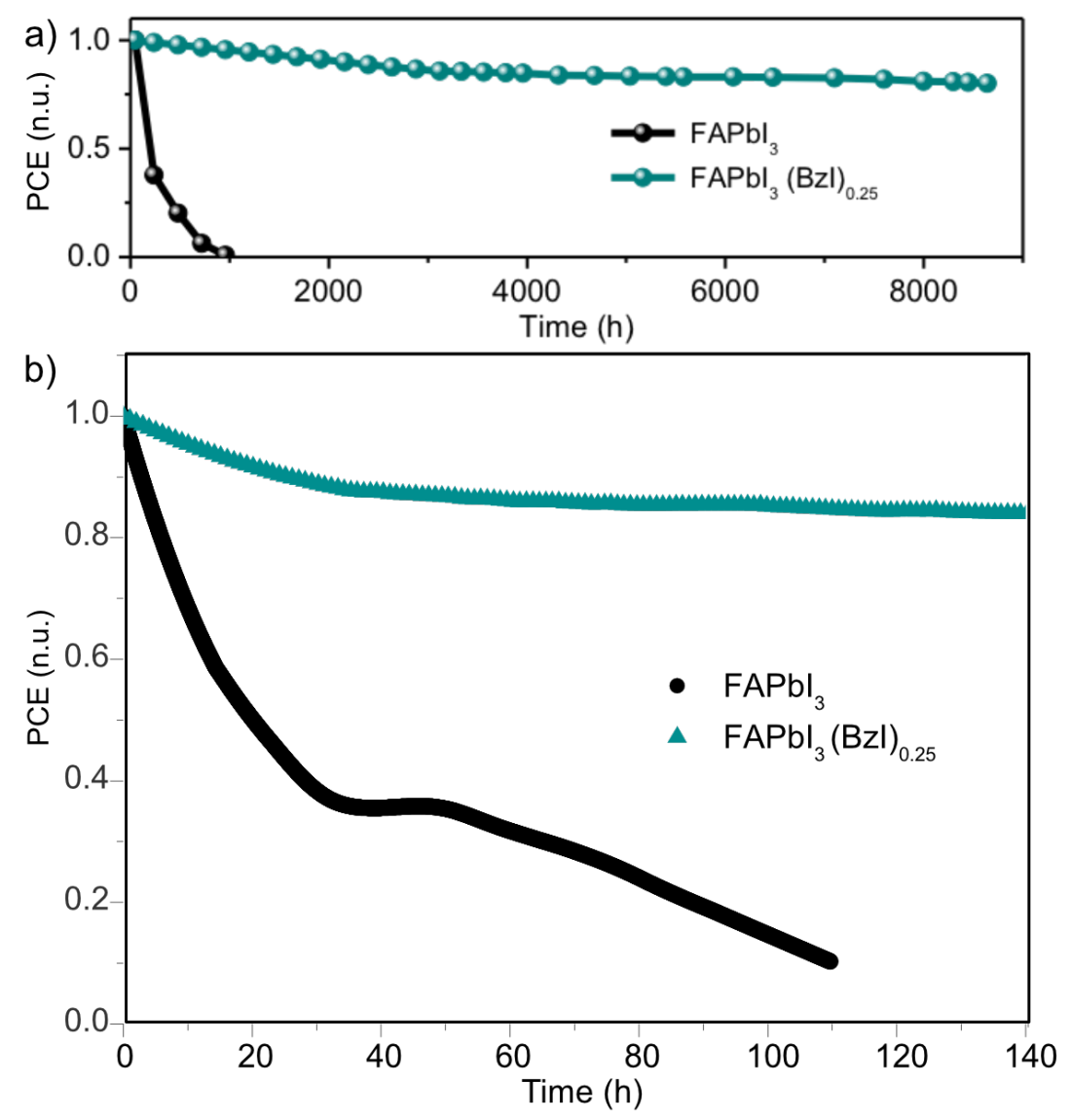

Figure 7. (a) Average shelf stability by monitoring the evolution of performance of the corresponding non-encapsulated solar cells exposed to the ambient environment with relative $40 \%$ humidity in the dark at ambient temperature (n.u. $=$ normalized units with respect to the initial performance). Initial PCE $=$ 20\%. (b) Normalized $\mathrm{PCE}$ of neat $\mathrm{FAPbI}_{3}$ and $(\mathrm{BzI})_{0.25} \quad \mathrm{FAPbI}_{3}$ based devices monitored under continuous white light exposure in the Nitrogen atmosphere, at $25^{\circ} \mathrm{C}$, as a function of time $(140 \mathrm{~h})$. Initial PCE $=19 \%$. 


\section{WILEY-VCH}

\section{Conclusion}

In summary, we have demonstrated that the addition of benzylammonium (Bz) iodide results in the stabilization of the black perovskite $\alpha-\mathrm{FAPbI}_{3}$ phase. The microscopic effects of the additive have been elucidated using multi-nuclear solid-state NMR spectroscopy complemented by X-ray scattering measurements. We demonstrate that $\mathrm{Bz}$ reacts with $\alpha$ $\mathrm{FAPbI}_{3}$ to render $\alpha-\mathrm{FAPbI}_{3}$ more stable. In this phase, the Bz moieties modulate the surface of the $\mathrm{FAPbI}_{3}$ and grain boundaries without forming low-dimensional perovskite phases. This modulation strategy strongly enhances the optoelectronic quality of the perovskite phase as has been shown by PLQY and TRPL measurements. As a result, perovskite solar cells based on $\mathrm{FAPbI}_{3}(\mathrm{BzI})_{0.25}$ show power conversion efficiencies exceeding $20 \%$ and superior stability, maintaining $80 \%$ of the initial PCE after one year under ambient shelf-life conditions. This strategy thus provides a new way of stabilizing the black $(\alpha)$ perovskite phase of $\mathrm{FAPbI}_{3}$ in perovskite solar cells. 


\section{WILEY-VCH}

\section{Experimental Section}

Materials. All materials were purchased from Sigma-Aldrich and used as received, unless stated otherwise. Perovskite powders for solid-state NMR studies were synthesized by grinding precursors in an electric ball mill (Retsch Ball Mill MM-200, grinding jar with a volume of 10 $\mathrm{ml}$ and 1 agate ball, diameter size $10 \mathrm{~mm}$ ) for $30 \mathrm{~min}$ at $25 \mathrm{~Hz}$. The precursors were packed in a glove box under an argon atmosphere. After milling, the resulted powders were annealed at $140{ }^{\circ} \mathrm{C}$ for 10 minutes to remove grinding-induced defects. The following amounts of reagents were used: $\mathrm{FAPbI}_{3}: 0.172 \mathrm{~g} \mathrm{FAI}(1 \mathrm{mmol})$ and $0.461 \mathrm{~g} \mathrm{PbI}_{2}(1 \mathrm{mmol}) ; \mathrm{FAPbI}_{3}(\mathrm{BzI})_{0.25}: 0.172 \mathrm{~g}$ FAI $(1 \mathrm{mmol})$ and $0.461 \mathrm{~g} \mathrm{PbI}_{2}(1 \mathrm{mmol})$ and $0.029 \mathrm{~g} \mathrm{BzI}(0.25 \mathrm{mmol})$.

Solar cell preparation. Fluorine-doped tin oxide (FTO)-glass substrates (TCO glass, NSG 10, Nippon sheet glass, Japan) were etched from the edges by using $\mathrm{Zn}$ powder and $4 \mathrm{M} \mathrm{HCl}$ and then, were cleaned by ultrasonication in Hellmanex ( $2 \%$, deionized water), rinsed thoroughly with de-ionized water and ethanol, and then treated in oxygen plasma for $15 \mathrm{~min}$. A $30 \mathrm{~nm}$ blocking layer $\left(\mathrm{TiO}_{2}\right)$ was deposited on the cleaned FTO by spray pyrolysis at $450{ }^{\circ} \mathrm{C}$ using a commercial titanium diisopropoxide bis(acetylacetonate) solution (75\% in 2-propanol, SigmaAldrich) diluted in anhydrous ethanol (1:9 volume ratio) as precursor and oxygen as a carrier gas. A mesoporous $\mathrm{TiO}_{2}$ layer was deposited by spin-coating a diluted paste (1:6 wt. ratio) (Dyesol 30NRD: ethanol) (4000 rpm, acceleration $2000 \mathrm{rpm}$ for $20 \mathrm{~s}$ ) onto the substrate containing a $\mathrm{TiO}_{2}$ compact layer, and then sintered at $450{ }^{\circ} \mathrm{C}$ for $30 \mathrm{~min}$ in dry air.

Deposition of perovskite films. The perovskite films were deposited using a single-step deposition method from the precursor solution. The precursor solution of $\mathrm{FAPbI}_{3}$ was prepared in Argon atmosphere by dissolving equimolar amounts of $\mathrm{PbI}_{2}$ and $\mathrm{FAI}$ in an anhydrous DMF/DMSO (4:1 (volume ratio)) mixture at a concentration of $1.3 \mathrm{M}$. Next, we added benzylammonium iodide $(\mathrm{BzI})$ into the $\mathrm{FAPbI}_{3}$ precursor solution using different molar 


\section{WILEY-VCH}

ratios, resulting in several $\mathrm{FAPbI}_{3}(\mathrm{BzI})_{\mathrm{x}}$ compositions $(\mathrm{x}=0.05,0.10,0.25,0.50)$. The device fabrication was carried out under controlled atmospheric conditions with humidity $<2 \%$. The precursor solution was spin-coated onto the mesoporous $\mathrm{TiO}_{2}$ films in a one-step program at 600 and $5000 \mathrm{rpm}$ for 30 s. $200 \mu 1$ of chlorobenzene was dropped on the spinning substrate $10 \mathrm{~s}$ prior the end of the program. This was followed by annealing the films at $150{ }^{\circ} \mathrm{C}$ for 30 $40 \mathrm{~min}$. After preparing the initial perovskite layer (control) as described above, the film was cooled down at room temperature. For completing the fabrication of devices, $90 \mathrm{mg}$ of 2,2',7,7'-tetrakis( $N, N$-di-p-methoxyphenylamine)-9,9-spirobifluorene (spiro-OMeTAD) was dissolved in $1 \mathrm{ml}$ of chlorobenzene as a hole-transporting material. The HTM was deposited by spin-coating at $4000 \mathrm{rpm}$ for $20 \mathrm{~s}$. The HTM was doped with bis(trifluoromethylsulfonyl)imide lithium salt (17.8 $\mu$ l prepared by dissolving $520 \mathrm{mg}$ LiTFSI in $1 \mathrm{ml}$ of acetonitrile), and $28.8 \mu \mathrm{l}$ of 4-tert-butylpyridine. Finally, a $\sim 80 \mathrm{~nm}$ gold ( $\mathrm{Au}$ ) layer was thermally evaporated.

Device characterization. The current-voltage $(J-V)$ characteristics of the perovskite devices were recorded with a digital source meter (Keithley model 2400, USA). A $450 \mathrm{~W}$ xenon lamp (Oriel, USA) was used as the light source for photovoltaic $(J-V)$ measurements. The spectral output of the lamp was filtered using a Schott K113 Tempax sunlight filter (Präzisions Glas \& Optik GmbH, Germany) to reduce the mismatch between the simulated and actual solar spectrum to less than $2 \%$. The photo-active area of $0.16 \mathrm{~cm}^{2}$ was defined using a dark-colored metal mask.

Incident photon-to-current efficiency (IPCE) was recorded under a constant white light bias of approximately $5 \mathrm{~mW} \cdot \mathrm{cm}^{-2}$ supplied by an array of white light emitting diodes. The excitation beam coming from a $300 \mathrm{~W}$ Xenon lamp (ILC Technology) was focused through a Gemini180 double monochromator (Jobin Yvon Ltd) and chopped at approximately $2 \mathrm{~Hz}$. The signal was recorded using a Model SR830 DSP Lock-In Amplifier (Stanford Research Systems). 


\section{WILEY-VCH}

Photoluminescence quantum yield (PLQY) was measured using an integrating sphere (Gigahertz-Optik), an Andor Kymera 193i spectrograph and a $660 \mathrm{~nm}$ continuous-wave laser (OBIS, Coherent) set at 1-Sun equivalent photon flux (790 $\mu \mathrm{m}$ beam full-width half-maximum, $330 \mu \mathrm{W})$; the photoluminescence signal was collected at normal incidence using an optical fiber. For the calibration of the PLQY measurements we used a halogen lamp (BN-LH250V01, Gigahertz-Optik), to proof the correctness of the calibration we measured PLQY of a dye solution of indocyanine green in DMSO in the same setup and measured PLQY values within $15 \%$ deviation from the literature values.

Time-Resolved Photoluminescent (TRPL) was measured via time-correlated single photon counting (TCSPC) using a LifeSpec II (Edinburgh Instruments) fluorescence spectrometer with a picosecond pulsed diode laser (EPL-510, Edinburgh Instruments) at $510 \mathrm{~nm}$ wavelength and 85 ps pulse width. The laser fluence used was $5 \mathrm{~nJ} / \mathrm{cm}^{2}$.

Scanning electron microscopy (SEM) was performed on a ZEISS Merlin HR-SEM.

X-ray powder diffractions were recorded on an X'Pert MPD PRO (Panalytical) equipped with a ceramic tube $(\mathrm{Cu}$ anode, $\lambda=1.54060 \AA)$, a secondary graphite (002) monochromator and a RTMS X'Celerator (Panalytical).

Grazing Incidence Wide Angle X-ray Scattering was measured on a xenocs XEUSS 2.0 laboratory beamline under a pressure of 0.1 bar, using $\mathrm{Cu} \mathrm{K}_{\alpha}$ radiation and incident angles below $0.5^{\circ}$.

UV-vis measurements were performed on a Varian Cary 5.

NMR spectroscopy involved low-temperature ${ }^{13} \mathrm{C}(225 \mathrm{MHz}),{ }^{15} \mathrm{~N}(90.23 \mathrm{MHz})$ and roomtemperature ${ }^{14} \mathrm{~N}(65 \mathrm{MHz}) \mathrm{NMR}$ spectra were recorded on a Bruker Avance Neo 21.1 T spectrometer equipped with a $3.2 \mathrm{~mm}$ low-temperature CPMAS probe. ${ }^{13} \mathrm{C}$ chemical shifts were 


\section{WILEY-VCH}

referenced to solid adamantane $\left[\delta_{\mathrm{C}}=29.45(\mathrm{CH})\right.$ and $\left.38.48\left(\mathrm{CH}_{2}\right) \mathrm{ppm}\right] .{ }^{14} \mathrm{~N}$ and ${ }^{15} \mathrm{~N}$ chemical shift were referenced to solid $\mathrm{NH}_{4} \mathrm{Cl}$ with shift at $0 \mathrm{ppm}$ and $39 \mathrm{ppm}$. Low-temperature ${ }^{1} \mathrm{H}-{ }^{13} \mathrm{C}$ CP experiments used $1 \mathrm{~ms}$ optimized contact pulses, SPINAL-64 ${ }^{1} \mathrm{H}$ decoupling, and the following recycle delays: $1.7 \mathrm{~s}\left(\delta-\mathrm{FAPbI}_{3}\right), 4 \mathrm{~s}\left(\alpha-\mathrm{FAPbI}_{3}\right), 1000 \mathrm{~s}(\mathrm{BzI}), 5 \mathrm{~s}\left(\mathrm{FAPbI}_{3}(\mathrm{BzI})_{0.25}\right.$. Low-temperature ${ }^{1} \mathrm{H}-{ }^{15} \mathrm{~N}$ CP experiments used 1 ms optimized contact pulses, SPINAL-64 ${ }^{1} \mathrm{H}$ decoupling, and the following recycle delays: $1.7 \mathrm{~s}\left(\delta-\mathrm{FAPbI}_{3}\right), 3 \mathrm{~s}\left(\alpha-\mathrm{FAPbI}_{3}\right), 1000 \mathrm{~s}(\mathrm{BzI}), 5 \mathrm{~s}$ $\left(\mathrm{FAPbI}_{3}(\mathrm{BzI})_{0.25}\right.$. Peak widths were fitted in Topspin 3.6.0 and the uncertainties are given at one standard deviation.

\section{Acknowledgements}

M.G. and S.M.Z. thank the King Abdulaziz City for Science and Technology (KACST) for financial support. A.Q.A and M.H.A gratefully acknowledge KACST for the fellowship. H.Z. thanks the financial support from the European Union's Horizon 2020 research and innovation programme under grant agreement No. 881603. J.V.M. is grateful for the Swiss National Science Foundation grant no. 193174. L.M., A.H., F.S. gratefully acknowledge funding by the DFG (SPP 2196) No. SCHR 700/38-1.

Notes. D.J.K. is presently affiliated with the University of Cambridge, Cavendish Laboratory, J J Thomson Avenue, Cambridge CB3 0HE, United Kingdom. J.V.M. is presently affiliated with the Adolphe Merkle Institute of the University of Fribourg in Switzerland.

Data availability. The data that support the findings of this study are available from the first author upon reasonable request.

Received: ((will be filled in by the editorial staff))

Revised: ((will be filled in by the editorial staff)) Published online: ((will be filled in by the editorial staff)) 


\section{WILEY-VCH}

\section{References}

[1] A. Kojima, K. Teshima, Y. Shirai and T. Miyasaka, J. Am. Chem. Soc., 2009, 131, 6050.

[2] National Renewable Energy Laboratory (NREL) https://www.nrel.gov/pv/cellefficiency.html (accessed in May 2020).

[3] M. Luan, J. Song, X. Wei, F. Chen and J. Liu, CrystEngComm. 2016, 18, 5257.

[4] S. P. Singh and P. Nagarjuna, Dalton Trans. 2014, 43, 5247.

[5] C. C. Stoumpos, C. D. Malliakas and M. G. Kanatzidis, Inorg. Chem. 2013, 52, 9019.

[6] T. Baikie, Y. Fang, J. M. Kadro, M. Schreyer, F. Wei, S. G. Mhaisalkar, M. Graetzel and T. J. White, J. Mater. Chem. A 2013, 1, 5628.

[7] M. A. Green, A. Ho-Baillie and H. J. Snaith, Nat. Photonics, 2014, 8, 506.

[8] S. Sun, T. Salim, N. Mathews, M. Duchamp, C. Boothroyd, G. Xing, T. C. Sum and Y. M. Lam, Energy Environ. Sci. 2014, 7, 399.

[9] A. K. Jena, A. Kulkarni and T. Miyasaka, Chem. Rev. 2019, 119, 3036.

[10] A. Amat, E. Mosconi, E. Ronca, C. Quarti, P. Umari, Md. K. Nazeeruddin, M. Grätzel and F. De Angelis, Nano Lett. 2014, 14, 3608.

[11] W.-F. Yang, F. Igbari, Y.-H. Lou, Z.-K. Wang and L.-S. Liao, Adv. Energy Mater. 2019, 1902584.

[12] G. Grancini and M. K. Nazeeruddin, Nat. Rev. Mater. 2019, 4, 4.

[13] L. Mao, C. C. Stoumpos and M. G. Kanatzidis, J. Am. Chem. Soc. 2019, 141, 1171.

[14] B. Saparov and D. B. Mitzi, Chem. Rev. 2016, 116, 4558.

[15] A. Krishna, S. Gottis, M. K. Nazeeruddin and F. Sauvage, Adv. Func. Mater. 2019, 29, 1806482.

[16] D. H. Cao, C. C. Stoumpos, O. K. Farha, J. T. Hupp and M. G. Kanatzidis, J. Am. Chem. Soc. 2015, 137, 7843.

[17] C. C. Stoumpos, D. H. Cao, D. J. Clark, J. Young, J. M. Rondinelli, J. I. Jang, J. T. Hupp and M. G. Kanatzidis, Chem. Mater. 2016, 28, 2852.

[18] L. Mao, W. Ke, L. Pedesseau, Y. Wu, C. Katan, J. Even, M. R. Wasielewski, C. C. Stoumpos and M. G. Kanatzidis, J. Am. Chem. Soc. 2018, 140, 3775.

[19] X. Li, J. Hoffman, W. Ke, M. Chen, H. Tsai, W. Nie, A. D. Mohite, M. Kepenekian, C. Katan, J. Even, M. R. Wasielewski, C. C. Stoumpos and M. G. Kanatzidis, J. Am. Chem. Soc. 2018, 140, 12226.

[20] W. Ke, L. Mao, C. C. Stoumpos, J. Hoffman, I. Spanopoulos, A. D. Mohite and M. G. Kanatzidis, Adv. Energy Mater. 2019, 9, 1803384.

[21] Y. Li, J. V. Milić, A. Ummadisingu, J.-Y. Seo, J.-H. Im, H.-S. Kim, Y. Liu, M. I. Dar, S. M. Zakeeruddin, P. Wang, A. Hagfeldt and M. Grätzel, Nano Lett. 2019, 19, 150.

[22] J. Even, L. Pedesseau and C. Katan, ChemPhysChem, 2014, 15, 3733. 


\section{WILEY-VCH}

[23] H. Tsai, W. Nie, J.-C. Blancon, C. C. Stoumpos, C. M. M. Soe, J. Yoo, J. Crochet, S.

Tretiak, J. Even, A. Sadhanala, G. Azzellino, R. Brenes, P. M. Ajayan, V. Bulović, S. D. Stranks, R. H. Friend, M. G. Kanatzidis and A. D. Mohite, Adv. Mater. 2018, 30, 1704217.

[24] T. Niu, J. Lu, M.-C. Tang, D. Barrit, D.-M. Smilgies, Z. Yang, J. Li, Y. Fan, T. Luo, I. McCulloch, A. Amassian, S. (Frank) Liu and K. Zhao, Energy Environ. Sci., 2018, 11, 3358. [25] Z. Wang, Q. Lin, F. P. Chmiel, N. Sakai, L. M. Herz and H. J. Snaith, Nat. Energy, 2017, $2,17135$.

[26] Y. Cho, A. M. Soufiani, J. S. Yun, J. Kim, D. S. Lee, J. Seidel, X. Deng, M. A. Green, S. Huang and A. W. Y. Ho-Baillie, Adv. Energy Mater. 2018, 8, 1703392.

[27] Y. Liu, S. Akin, L. Pan, R. Uchida, N. Arora, J. V. Milić, A. Hinderhofer, F. Schreiber, A. R. Uhl, S. M. Zakeeruddin, A. Hagfeldt, M. I. Dar and M. Grätzel, Sci. Adv. 2019, 5, eaaw2543.

[28] A. Q. Alanazi, D. J. Kubicki, D. Prochowicz, E. A. Alharbi, M. E. F. Bouduban, F. Jahanbakhshi, M. Mladenović, J. V. Milić, F. Giordano, D. Ren, A. Y. Alyamani, H. Albrithen, A. Albadri, M. H. Alotaibi, J.-E. Moser, S. M. Zakeeruddin, U. Rothlisberger, L. Emsley and M. Grätzel, J. Am. Chem. Soc. 2019, 141, 17659.

[29] L. Hong, J. V. Milić, P. Ahlawat, M. Mladenović, D. J. Kubicki, F. Jahanabkhshi, D. Ren, M. C. Gélvez-Rueda, M. A. Ruiz-Preciado, A. Ummadisingu, Y. Liu, C. Tian, L. Pan, S. M. Zakeeruddin, A. Hagfeldt, F. C. Grozema, U. Rothlisberger, L. Emsley, H. Han and M. Graetzel, Angew. Chem. Int. Ed. 2020, 59, 4691.

[30] A. H. Proppe, R. Quintero-Bermudez, H. Tan, O. Voznyy, S. O. Kelley and E. H. Sargent, J. Am. Chem. Soc. 2018, 140, 2890.

[31] P. Chen, Y. Bai, S. Wang, M. Lyu, J.-H. Yun and L. Wang, Adv. Func. Mater. 2018, 28, 1706923.

[32] J. Qing, X.-K. Liu, M. Li, F. Liu, Z. Yuan, E. Tiukalova, Z. Yan, M. Duchamp, S. Chen, Y. Wang, S. Bai, J.-M. Liu, H. J. Snaith, C.-S. Lee, T. C. Sum and F. Gao, Adv. Energy Mater. 2018, 8, 1800185.

[33] J. Qing, C. Kuang, H. Wang, Y. Wang, X.-K. Liu, S. Bai, M. Li, T. C. Sum, Z. Hu, W. Zhang and F. Gao, Adv. Mater. 2019, 31, 1904243.

[34] F. Wang, W. Geng, Y. Zhou, H.-H. Fang, C.-J. Tong, M. A. Loi, L.-M. Liu and N. Zhao, Adv. Mater. 2016, 28, 9986.

[35] H.-S. Yoo and N.-G. Park, Solar Energy Materials and Solar Cells, 2018, 179, 57.

[36] A. Binek, F. C. Hanusch, P. Docampo and T. Bein, J. Phys. Chem. Lett. 2015, 6, 1249.

[37] Y.-J. Cheng, S.-H. Yang and C.-S. Hsu, Chem. Rev. 2009, 109, 5868.

[38] T. Saitoh, T. Matsudo and C. Matsubara, J. Chromatog. A, 2000, 879, 121.

[39] B.-E. Cohen, M. Wierzbowska and L. Etgar, Sust. Energy Fuels, 2017, 1, 1935.

[40] Z. Cheng and J. Lin, CrystEngComm, 2010, 12, 2646. 


\section{WILEY-VCH}

[41] J. V. Milić, J.-H. Im, D. J. Kubicki, A. Ummadisingu, J.-Y. Seo, Y. Li, M. A. Ruiz-Preciado,

M. I. Dar, S. M. Zakeeruddin, L. Emsley and M. Grätzel, Adv. Energy Mater. 2019, 9, 1900284.

[42] Y. Fu, T. Wu, J. Wang, J. Zhai, M. J. Shearer, Y. Zhao, R. J. Hamers, E. Kan, K. Deng, X.-Y. Zhu and S. Jin, Nano Lett. 2017, 17, 4405.

[43] S.-Y. Kim, J.-M. Yang, E.-S. Choi and N.-G. Park, Nanoscale 2019, 11, 14330.

[44]Q. Han, S.-H. Bae, P. Sun, Y.-T. Hsieh, Y. (Michael) Yang, Y. S. Rim, H. Zhao, Q. Chen, W. Shi, G. Li and Y. Yang, Adv. Mater. 2016, 28, 2253.

[45] T. Niu, J. Lu, M.-C. Tang, D. Barrit, D.-M. Smilgies, Z. Yang, J. Li, Y. Fan, T. Luo, I. McCulloch, A. Amassian, S. (Frank) Liu and K. Zhao, Energy Environ. Sci. 2018, 11, 3358.

[46] (a) Foresman, J. B.; Frisch, Æ. Exploring Chemistry with Electronic Structure Methods, Second Edition. Gaussian, Inc., 1995; pp 1-335. (b) Gaussian 16, Revision A.03, Frisch, M. J.; Trucks, G. W.; Schlegel, H. B.; Scuseria, G. E.; Robb, M. A.; Cheeseman, J. R.; Scalmani, G.; Barone, V.; Petersson, G.A.; Nakatsuji, H.; Li, X.; Caricato, M.; Marenich, A. V.; Bloino, J.; Janesko, B. G.; Gomperts, R.; Mennucci, B.; Hratchian, H. P.; Ortiz, J. V.; Izmaylov, A. F.; Sonnenberg, J. L.; Williams-Young, D.; Ding, F.; Lipparini, F.; Egidi, F.; Goings, J.; Peng, B.; Petrone, A.; Henderson, T.; Ranasinghe, D.; Zakrzewski, V. G.; Gao, J.; Rega, N.; Zheng, G.; Liang, W.; Hada, M.; Ehara, M.; Toyota, K.; Fukuda, R.; Hasegawa, J.; Ishida, M.; Nakajima, T.; Honda, Y.; Kitao, O.; Nakai, H.; Vreven, T.; Throssell, K.; Montgomery, Jr., J. A.; Peralta, J. E.; Ogliaro, F.; Bearpark, M. J.; Heyd, J. J.; Brothers, E. N.; Kudin, K. N.; Staroverov, V. N.; Keith, T. A.; Kobayashi, R.; Normand, J.; Raghavachari, K.; Rendell, A. P.; Burant, J. C.; Iyengar, S. S.; Tomasi, J.; Cossi, M.; Millam, J. M.; Klene, M.; Adamo, C.; Cammi, R.; Ochterski, J. W.; Martin, R. L.; Morokuma, K.; Farkas, O.; Foresman, J. B.; Fox, D. J. Gaussian, Inc., Wallingford CT, 2016.

[47] D. J. Kubicki, D. Prochowicz, A. Hofstetter, S. M. Zakeeruddin, M. Grätzel and L. Emsley, J. Am. Chem. Soc. 2018, 140, 7232.

[48] D. J. Kubicki, D. Prochowicz, A. Hofstetter, S. M. Zakeeruddin, M. Grätzel and L. Emsley, J. Am. Chem. Soc. 2017, 139, 14173.

[49] B. A. Rosales, L. Men, S. D. Cady, M. P. Hanrahan, A. J. Rossini and J. Vela, Chem. Mater. 2016, $28,6848$.

[50] A. Karmakar, M. S. Dodd, X. Zhang, M. S. Oakley, M. Klobukowski and V. K. Michaelis, Chem. Commun., 2019, 55, 5079.

[51] J. Zhang, Z. Wang, A. Mishra, M. Gräetzel, W. Guo, A. Hagfeldt, M. Yu, M. Shasti, W. Tress, D. Kubicki, C. Avalos, H. Lu, Y. Liu, B. Carlsen, A. Agarwalla, Z. Wang, W. Xiang, L. Emsley and Z. Zhang, Joule 2020, 4, 222.

[52] G. M. Bernard, R. E. Wasylishen, C. I. Ratcliffe, V. Terskikh, Q. Wu, J. M. Buriak and T. Hauger, J. Phys. Chem. A, 2018, 122, 1560. 


\section{WILEY-VCH}

[53] R. E. Wasylishen, O. Knop and J. B. Macdonald, Sol. State Commun. 1985, 56, 581.

[54] D. J. Kubicki, D. Prochowicz, A. Hofstetter, P. Péchy, S. M. Zakeeruddin, M. Grätzel and L. Emsley, J. Am. Chem. Soc. 2017, 139, 10055.

[55] E. A. Alharbi, A. Y. Alyamani, D. J. Kubicki, A. R. Uhl, B. J. Walder, A. Q. Alanazi, J. Luo, A. Burgos-Caminal, A. Albadri, H. Albrithen, M. H. Alotaibi, J.-E. Moser, S. M. Zakeeruddin, F. Giordano, L. Emsley and M. Grätzel, Nat. Commun. 2019, 10, 3008.

[56] D. Bi, X. Li, J. V. Milić, D. J. Kubicki, N. Pellet, J. Luo, T. LaGrange, P. Mettraux, L. Emsley, S. M. Zakeeruddin, M. Grätzel, Nat. Commun. 2018, 9, 4482.

[57] H. Lu, Y. Liu, P. Ahlawat, A. Mishra, W. R. Tress, F. T. Eickemeyer, Y. Yang, F. Fu, Z. Wang, C. E. Avalos, B. I. Carlsen, A. Agarwalla, X. Zhang, X. Li, Y. Zhan, S. M. Zakeeruddin, L. Emsley, U. Rothlisberger, L. Zheng, A. Hagfeldt, M. Grätzel, Science 2020, 370 , eabb8985.

[58] M. A. Ruiz-Preciado, D. J. Kubicki, A. Hofstetter, L. McGovern, M. H. Futscher, A. Ummadisingu, R. Gershoni-Poranne, S. M. Zakeeruddin, B. Ehrler, L. Emsley, J. V. Milić and M. Grätzel, J. Am. Chem. Soc. 2020, 142, 1645.

[59] G. C. Papavassiliou, G. A. Mousdis, C. P. Raptopoulou and A. Terzis, Zeits. Naturf. B, 1999, 54, 1405.

[60] T. Schmitt, S. Bourelle, N. Tye, G. Soavi, A. D. Bond, S. Feldmann, B. Traore, C. Katan, J. Even, S. E. Dutton and F. Deschler, J. Am. Chem. Soc. 2020, 142, 5060.

[61] J. C. de Mello, H. F. Wittmann, R. H. Friend, Adv. Mater. 2004, 9, 230.

[62] R. T. Ross, J. Chem. Phys. 1967, 46, 4590.

[63] P. Caprioglio, M. Stolterfoht, C. M. Wolff, T. Unold, B. Rech, S. Albrecht, D. Neher, Adv. Energy Mater. 2019, 9, 1901631.

[64] W. Tress, M. Yavari, K. Domanski, P. Yadav, B. Niesen, J. P. C. Baena, A. Hagfeldt, M. Graetzel, 2018, 11, 151.

[65] T. Kirchartz, J. A. Márquez, M. Stolterfoht, and T. Unold, Adv. Energy Mater. 2020, 10, 1904134. 


\section{WILEY-VCH}

Keyword: low-dimensional perovskites, solid-state NMR, benzylammonium, formamidinium lead iodide

Anwar Q. Alanazi, ${ }^{1}$ Masaud H. Almalki, ${ }^{1}$ Aditya Mishra, ${ }^{2}$ Dominik J. Kubicki, ${ }^{1,2}$ Zaiwei Wang, ${ }^{3}$ Lena Merten, ${ }^{4}$ Felix T. Eickemeyer, ${ }^{1}$ Hong Zhang, ${ }^{1}$ Dan Ren, ${ }^{1}$ Ahmed Y. Alyamani, ${ }^{5}$ Hamad Albrithen, ${ }^{5,6,7}$ Abdulrahman Albadri, ${ }^{5}$ Mohammad Hayal Alotaibi, ${ }^{5}$ Alexander Hinderhofer, ${ }^{4}$ Shaik M. Zakeeruddin, ${ }^{1}$ Anders Hagfeldt, ${ }^{3}$ Lyndon Emsley, ${ }^{2 *}$ Jovana V. Milic, ${ }^{1 *}$ and Michael Graetzel ${ }^{1 *}$

\section{Benzylammonium-Mediated Formamidinium Lead Iodide Perovskite Phase Stabilization for Photovoltaics}

A stable $\alpha-\mathrm{FAPbI}_{3}$ perovskite phase is achieved by employing benzylammonium iodide (BzI), which was elucidated by solid-state NMR spectroscopy and X-ray scattering measurements to obtain perovskite solar cells based on the $\mathrm{FAPbI}_{3}(\mathrm{BzI})_{0.25}$ composition with power conversion efficiencies exceeding $20 \%$ accompanied by enhanced shelf-life and operational stability, maintaining $80 \%$ of the performance after one year at ambient conditions.

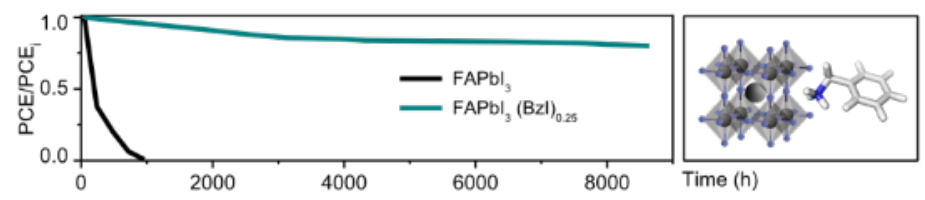

ToC figure 